\title{
Role of Fluoridation in Caries Prevention among Children- Long Term Follow-Up
}

\author{
Vito Antonio Malagnino MD, DDS ${ }^{1}$, Mimoza Canga MD, PhD $^{2}$ \\ ${ }^{1}$ Sapienza University of Rome, 00185 Italy \\ ${ }^{2}$ University of Medicine Tirana, 9400 Albania
}

\begin{abstract}
It is known that fluoride spray application is an effective method of preventing dental caries permanent dentition. Material and methods: Our research of 355 school children 12 years old showed that use the spray preparation of fluoride 5\% Sodium Fluoride 22.600 ppm had a remarkable anti-caries effect. In a control group we had 198 school children, girls $40.4 \%$ and boys $59.6 \%$. In fluoridation group we had 157 school children, girls $40.1 \%$ and boys 59.9\% of the same age. Resultants: Ninety percent of examined children had caries. DMFS (decayed, missing and filled surfaces) were from the data analyses we see that in the control group at the beginning of the study the index DMFS $=4.5$ while at the end of the study the index increases DMFS $=5.27$. The fluoridation group at the beginning of the study presents a caries experience DMFS $=4.2$ and at the end of the study DMFS $=4$ decreased respectively. Comparison of averages of DMFS at the end of study between control group and fluoridation group have shown the reduction of caries ( $p<0.05)$. Conclusion: The fluoride spray $5 \% \mathrm{NaF}$ resulted effective in reduction of dental caries of permanent teeth in school children.
\end{abstract}

Keywords: dental caries, control group, fluoridation group, anti-caries effect

\section{Introduction}

The studies show that the prevalence of dental caries is increasing in cases when the oral hygiene is bad [3], [16]. The risk factors are important to know and the presence of the protective factors as the oral hygiene and the use of fluoride in various forms and controlled doses [1],[2],[4][8].The level of fluoride on the tooth and saliva is reduced considerably after the fluoride application systematically and locally[9]-[15]. The studies show that the higher the concentration of fluoride in saliva and the dental plaque the lower the caries incidence [1], [2].The scientific evidence supports the idea that the main mechanism of fluoride action in caries prevention is the post eruptive and not the systematic one [17]-[19].

\section{Aim}

It is known that fluoride spray application is an effective method of preventing dental caries permanent dentition.

\section{Material and methods}

Our research of 355 school children 12 years old showed that use the spray preparation of fluoride 5\% Sodium Fluoride $22.600 \mathrm{ppm}$ had a remarkable anti-caries effect. In a control group we had 198 school children, girls $40.4 \%$ and boys $59.6 \%$. In fluoridation group we had 157 school children, girls $40.1 \%$ and boys $59.9 \%$ of the same age. The data collected from the applications and was analyzed on statistical program SPSS.

\section{Results}

The number of school children in the control group in the beginning of the study was $\mathrm{N}=198$.

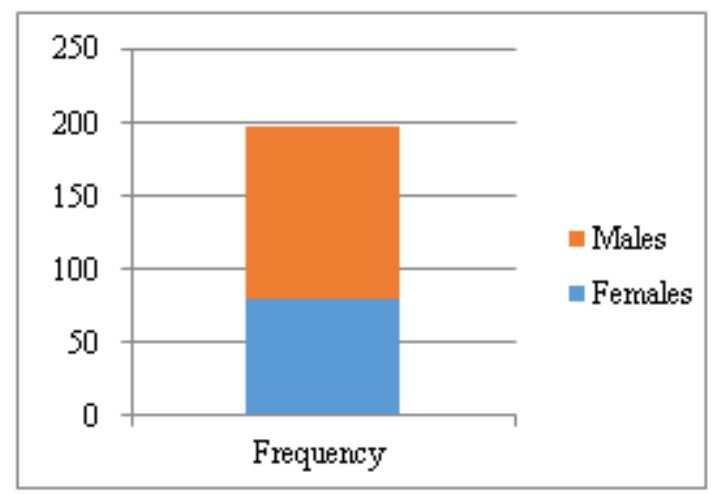

Figure 1: Gender distribution in the control group

The number of schoolchildren in the fluoridation group in the beginning of the study was $\mathrm{N}=157$

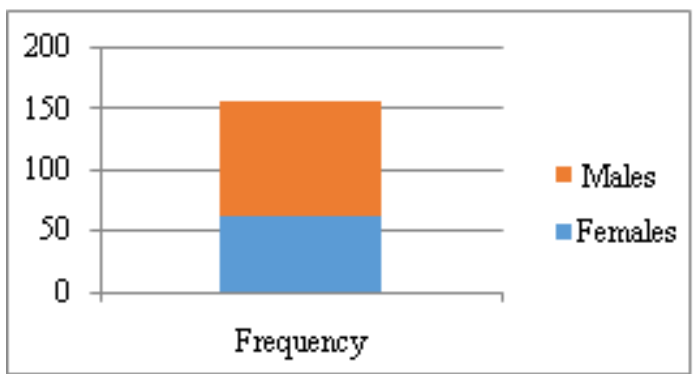

Figure 2: Gender distribution in the fluoridation group

Frequency of percentages of the number of the teeth with caries in the control group at the beginning of the study $\mathrm{N}=198$. 
International Journal of Science and Research (IJSR)

ISSN (Online): 2319-7064

Index Copernicus Value (2013): 6.14 | Impact Factor (2015): 6.391

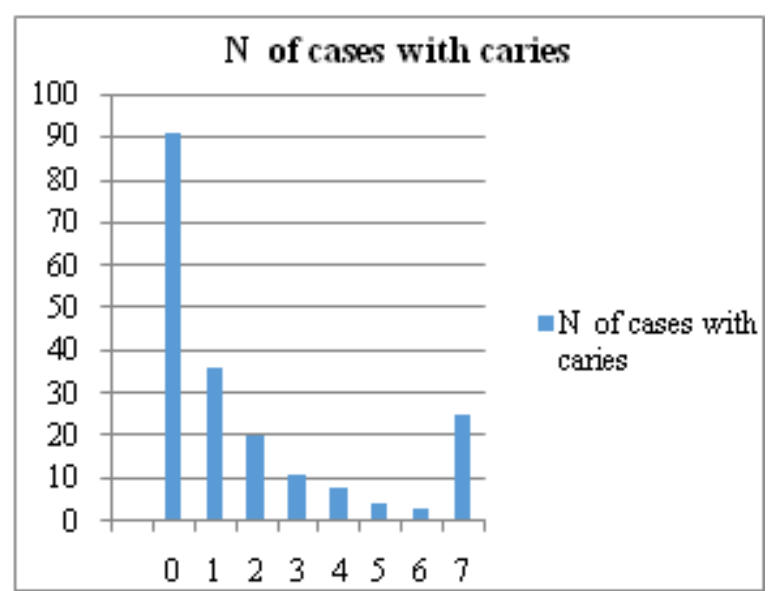

Figure 3: Control group at the beginning of the study.

The descriptive data for the number of surfaces of decayed permanent teeth (DS), filled (FT), extracted (MS) and DMFS index in the control group in the beginning of the study.

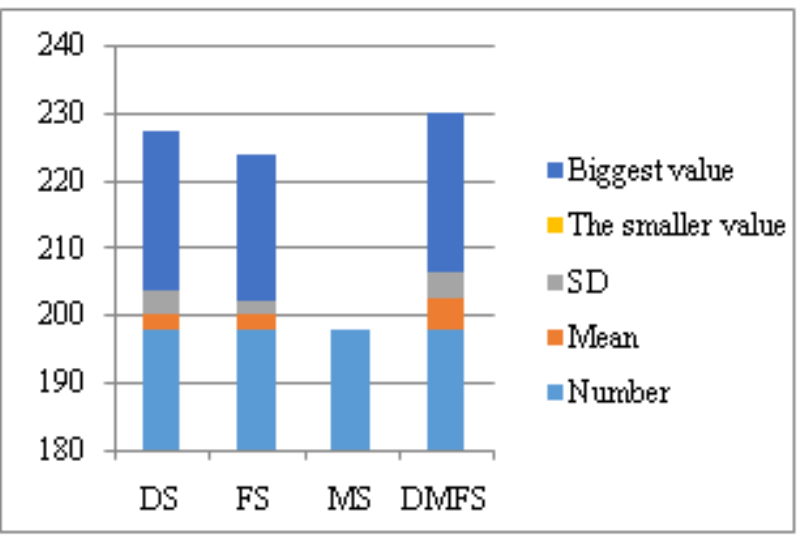

Figure 4: Caries experience expressed with surfaces of the teeth presented by DMFS index in the beginning of the study- control group

Frequency of percentages of the number of the teeth with caries in the fluoridation group at the beginning of the study $\mathrm{N}=157$.

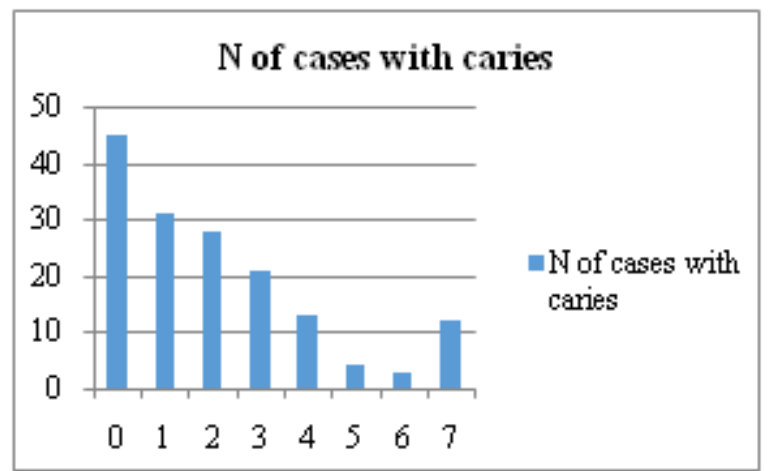

Figure 5: Fluoridation group at the beginning of the study

Caries experience expressed with surfaces of the teeth presented by DMFS index in the beginning of the studyfluoridation group.

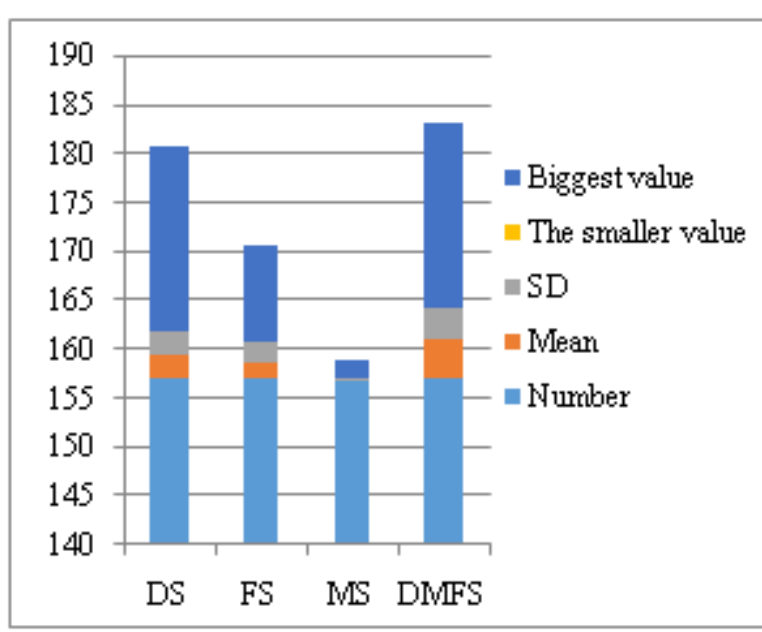

Figure 6 : The descriptive data for the number of surfaces of decayed permanent teeth (DS), filled (FT), extracted (MS) and DMFS index in the fluoridation group in the beginning of the study.

Frequency of percentages of the teeth with caries in the control group at the end of the study.

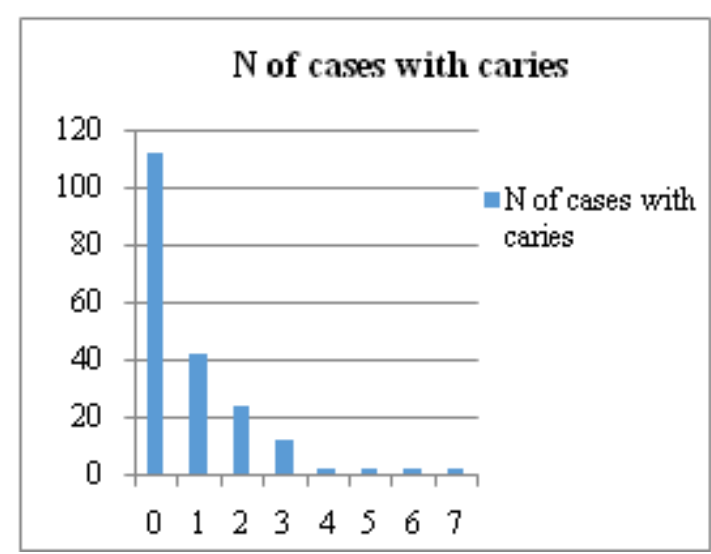

Figure 7: Control group at the end of the study

Caries experience expressed with surfaces of the teeth presented by DMFS index in the end of the study- control group.

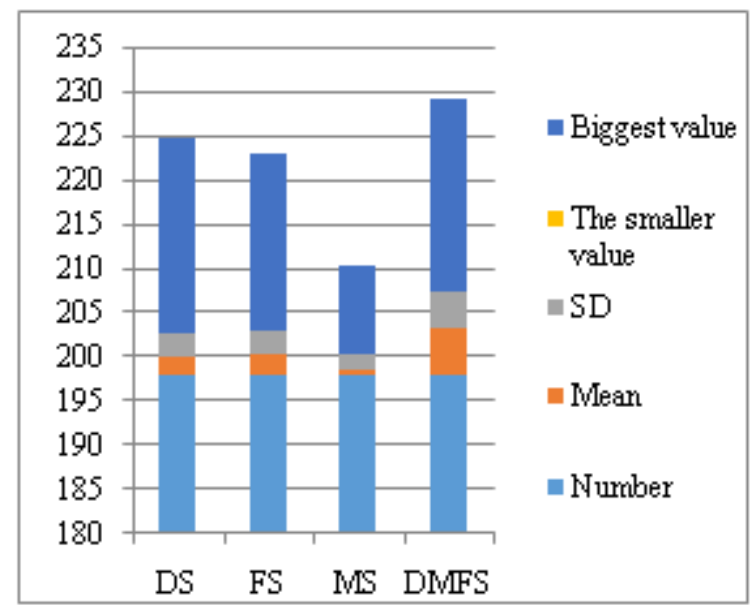

Figure 8 : The descriptive data for the number of surfaces of decayed permanent teeth (DS), filled (FT), extracted (MS) and DMFS index in the control group in the end of the study. 


\section{International Journal of Science and Research (IJSR) \\ ISSN (Online): 2319-7064 \\ Index Copernicus Value (2013): 6.14 | Impact Factor (2015): 6.391}

Frequency of percentages of the number of the teeth with caries in the fluoridation group at the end of the study

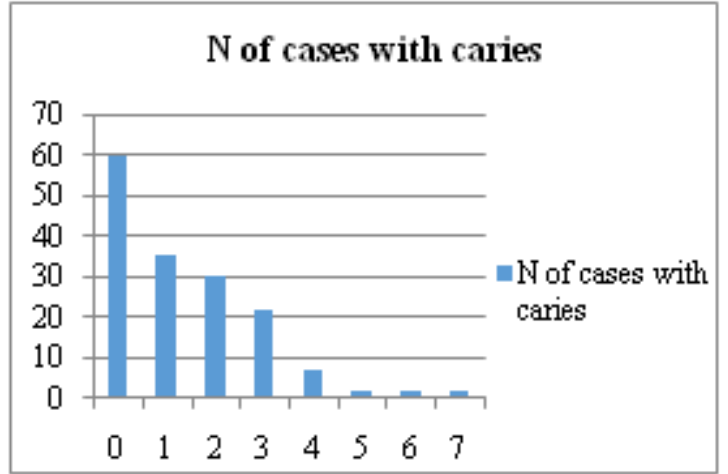

Figure 9: The fluoridation group at the end of the study is $\mathrm{N}$ $=157$.

Caries experience expressed with surfaces of the teeth presented by DMFS index in the end of the studyfluoridation group.

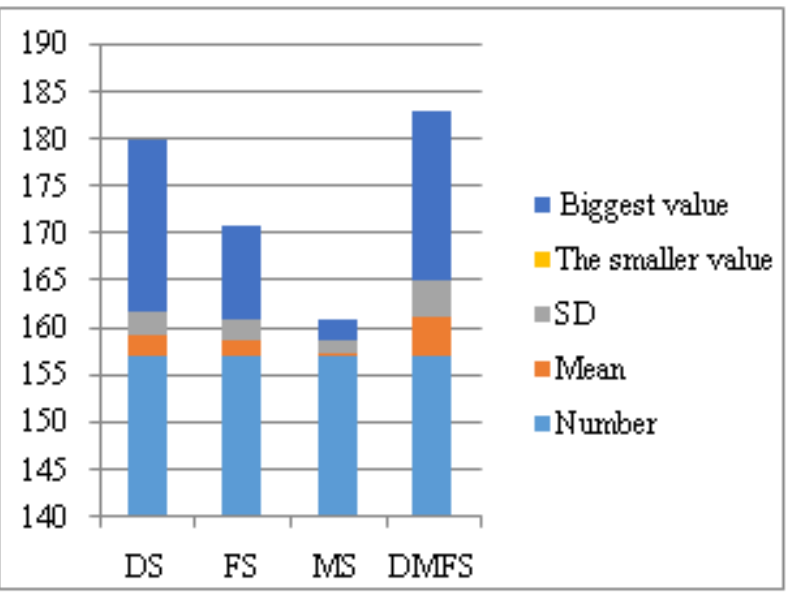

Figure 10: The descriptive data for the number of surfaces of decayed permanent teeth (DS), filled (FT), extracted (MS) and DMFS index in the fluoridation group in baseline in the end of the study.
The graphic presented the change in the caries experience in the beginning and the end of the study in the control and fluoridation group. It is clearly noted an increase of the caries experience in the control group.

Caries experience expressed with surfaces of the teeth presented by DMFS index in the beginning and the end of the study. This table presents the results of caries experience in the beginning and the end of the study in the control and fluoridation group according to DMFS index. From the data analyses we see that in the control group at the beginning of the study the index is DMFS $=4.5$ while at the end of the study the index increases DMFS $=5.27$. The fluoridation group at the beginning of the study presents a caries experience DMFS $=4.2$ and at the end of the study DMFS $=4$. The number of extracted surfaces or that are missing as the result of caries are $\mathrm{MS}=0.57$. The dental caries experience in school children is expressed with the mean of DMFS $=4.2$ index which shows that on average each school children in the fluoridation group has 4.2 surfaces with dental caries. The result shows that there was a significant statistical difference between two groups related to the mean of caries experience DMFS $(\mathrm{p}=0.023)$. Also when we compared the control group with the fluoridation group according to the caries experience on the tooth surface by DMFS index we notice that the control group has a higher mean than the fluoridation group; $5.27 / 4$. The total increase of the caries experience in the control group and fluoridation group is: DMFS beginning control group - DMFS end control group $=5.27-4.5=0.77$.DMFS fluoridation beginning- DMFS fluoridation end $=4.2-4=0.2$. There is no new surface with caries experience in the fluoridation group. The fluoride spray has an impact on the reduction of the caries experience. The detailed results related to the distribution of the caries experience according to the dentition at the end of the study show that the first permanent molar is responsible for most of the dental caries compared with the central and the lateral tooth.

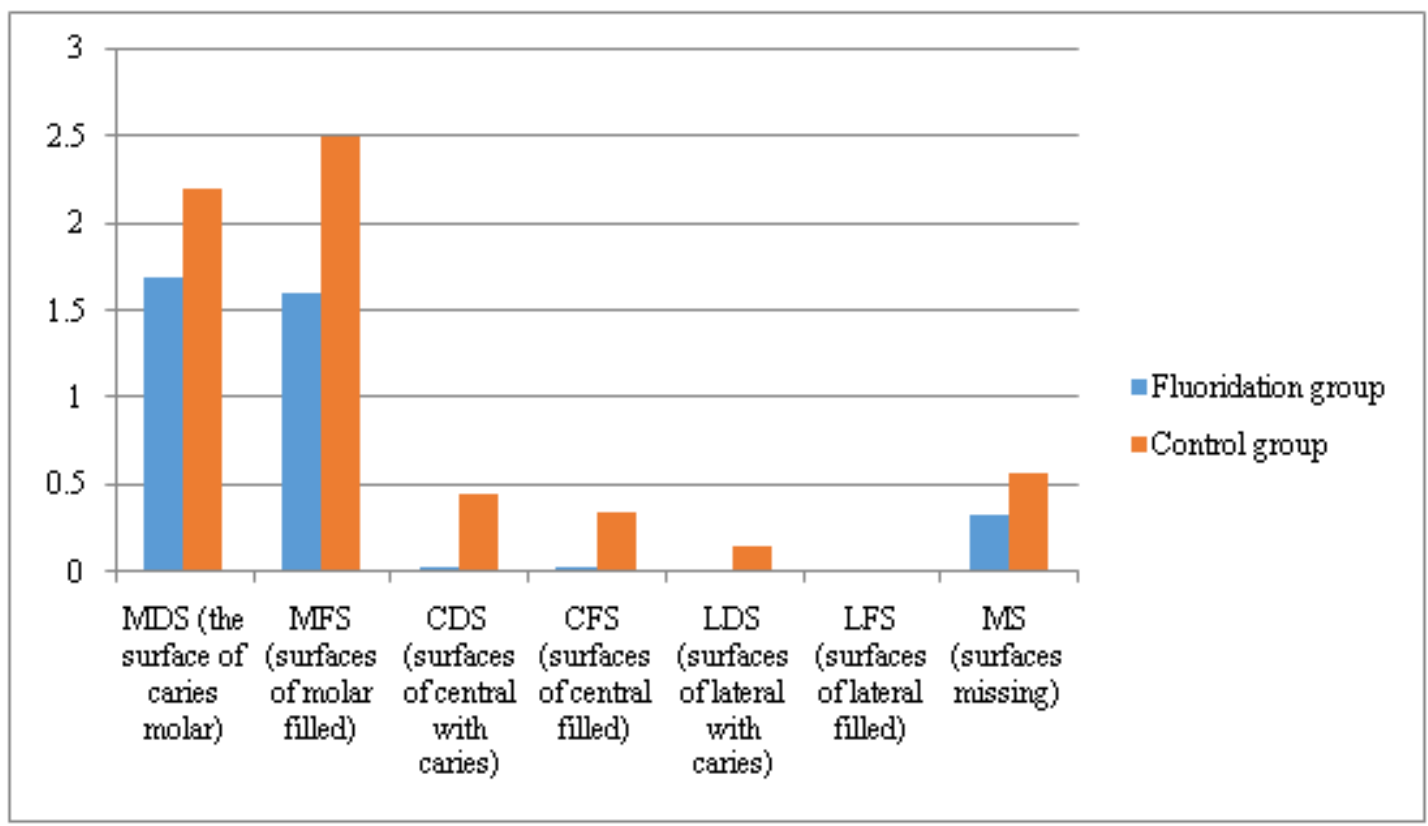

Volume 5 Issue 8, August 2016 www.ijsr.net 


\section{International Journal of Science and Research (IJSR) \\ ISSN (Online): 2319-7064}

Index Copernicus Value (2013): 6.14 | Impact Factor (2015): 6.391

When we compare the control group with the fluoridation group at the end of the study we notice the expression of the dental caries in formal teeth as the central and lateral, meanwhile in the fluoridated group there is not a caries experience in these teeth. When we compare the dental surfaces that are missing as caries result in the control group we notice a higher experience.

\section{Discussion}

The mean of caries experience expressed with caries surfaces and filled in the first molar, central and lateral and the mean of the surfaces that are missing at the end of the study. This experience in this subgroup is measured by using the $\mathrm{SiC}$ index with a value $\mathrm{SiC}$ control $=5.2$ and $\mathrm{SiC}$ fluoridation $=4.4$. According to the results at the beginning of the study we have a mean index DMFS $=4.5$ in the control group and $\mathrm{DMFS}=4.2$ in the fluoridation group. After 24 months we notice an increase of the caries experience only in the control group with DMFS $=5.27$ and in the fluoridation group DMFS $=4$. Similar results are referred to a Sweden study [14] related to the PF of fluoride spray on proximal caries. Donkey and Zimmer in their study on caries prevalence and the fluoride effect [9] conclude that after 4 years the caries experience was reduced by $40 \%$. The American Society of Dentistry recommend that in cases when the risk of caries diseases is not estimated, caries experience is a good predictor of caries risk [7]. Studies show that fluoride spray may be more effective than other ways of professional application of fluoride in remineralization of initial caries lesions [4]. In a systematic review of the literature is mentioned that the most frequent dose of fluoride spray to demonstrate the desired effect is 22,600 ppm [5]. Beltran-Aguilar, Goldstein and Lockwood [6] concluded that the risk for a toxic reaction from the spray is minimal as it sticks immediately on the tooth surface and the dose that is assimilated during the procedure is minimal [6].

\section{Conclusions}

The fluoride spray $5 \% \mathrm{NaF}$ resulted effective in reduction of dental caries of permanent teeth in school children. Extensive coverage of school children under the School Incremental Dental Care Program and the use fluoride spray $5 \%$ contribute to the decline.

\section{Acknowledgment}

To perform and report this study no financial support from any companies or from a national or international funding source was received

\section{References}

[1] Anger L, Swain MV, Wong L, Soissons C." The effects of fluoride and mineralizing treatments on plaque microcosm $\mathrm{CA}, \mathrm{P}$ and $\mathrm{F}, \mathrm{pH}$ responses and cariogenicity".N Z Dent J. 2011 Mar; 107(1):12-8.

[2] Ambarkova V, Gorseta K, Glavina D, Jankulovska M, Skrinjaric I. "Effect of the Fluoride Varnishes Comparing CPP-ACP Complex on Human Enamel
Demineralization / Remineralization”. IDJ 2013; 63(Suppl .1):99-197.

[3] Amin TT, Al-Abad BM." Oral hygiene practices, dental knowledge, dietary habits and their relation to caries among male primary school children in Al Hassam, Saudi Arabia".Int J Dent Hyg. 2008 Nov; 6(4):361-70.

[4] Autio-Gold JT, Courts F." Assessing the effect of fluoride varnish on early enamel carious lesions in the primary dentition". J Am Dent Assoc. Sept 2001; 132(9):1247-1253.

[5] Azarpazhooh A, Main PA." Fluoride varnish in the prevention of dental caries in children and adolescents: a systematic review". J Can Dent Assoc. 2008 Feb; 74(1):73-9.

[6] Beltran-Aguilar E, Goldstein J, Lockwood S.” Fluoride varnishes, a review of their clinical use, cariostatic mechanism, efficacy and Safety". J Am Dent Assoc 2000; 131(5): 589-96.

[7] Centers for Disease Control and Prevention." Recommendations for using fluoride to prevent and control dental caries in the United States". MMWR Recommend Rep. Aug 17, 2001; 50(RR-14):1-42.

[8] Chinana O, Marshall TA, Levy SM, Cavanaugh JE, Warren JJ, Profit B, Volker JL." Mixed dentition cavitated caries incidence and dietary intake frequencies". Pediatric Dent. 2011 May-Jun; 33(3):23340.

[9] Dohnke- Hohrmann S, Zimmer S.” Change in caries prevalence after implementation of a fluoride varnish program". J Public Health Dent. 2004 spring; 64(2):96100

[10]Gjorgievska E, John W, Ian.J et al.’Enamel remineralization by toothpastes".IDJ 2013; 63(Suppl.1): 198-296.

[11] Isogai A, Nakagaki H, Hanaki M, Shnji T, Osaka C. "Use of fluoridated dentifrice and glucose retention at the approximal areas of anterior teeth". J Dent child 2001; Jan- Feb: 42-6.

[12] Noble J, Locker D, Weibe D, Murray H, Weibe P, Frosina C, Clarke M.” A comparison of the costs and patient acceptability of professionally applied topical fluoride foam and varnish". Journal of Public Health Dentistry 64(2), pp. 106-110.

[13] Murray JJ, Rug-Gunn AJ Jenkins GN." Fluoride in Caries Prevention". 3rd ed. 1991. P.295-323

[14] Moberg Skold U, Petersson LG, Lith A, Birkhed D." Effect of school-based fluoride varnish programmes on approximal caries in adolescents from different caries risk areas". Caries Res. 2005 Jul-Aug; 39(4):273-9.

[15] Noor I, Khairiyah A, Natifah"Cheaters in caries status of school-children in Malaysia". IDJ 2013; 63 (Suppl.1):198-296.

[16] Schroder U, Granit."Dietaryhabits and oral hygiene as predictors of caries in 3- year-old children". Community Dent Oral Epidemiology. 1983 Oct; 11(5):308-11.

[17] Rogers AH, Bert AG.” Effects of xylitol and fluoride on the response to glucose pulses of Streptococcus mutants T8 growing in continuous culture". Oral Microbial Immunology 1992; 7:124-6.

[18] Tubert-Jeannin S, Auclair C, Amsallem E, Tramini P, Gerbaud L, Ruffieux C, Schulte AG, Koch MJ, RegeWalther M, and Ismail A."Fluoride supplements 


\section{International Journal of Science and Research (IJSR) \\ ISSN (Online): 2319-7064}

Index Copernicus Value (2013): 6.14 | Impact Factor (2015): 6.391

(tablets, drops, lozenges or chewing gums) for preventing dental caries in children".Cochrane Database Syst Rev. 2011 Dec 7; 12:CD007592.

[19] Walsh T, Worthington HV, Glenny AM, Appelbe P, Marinho VC, Shi X." Fluoride toothpastes of different concentrations for preventing dental caries in children and adolescents". Cochrane Database Syst Rev. 2010 Jan $20 ;(1): C D 007868$.

\section{Author profile}

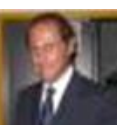

Professor Vito Antonio Malagnino is laureate in the Faculty of the Medicine with excellent grades. He is specialized in odontostomatology in the University of Roma- Sapienza Italy. $\mathrm{He}$ is the chief of the endodontic in Sapienza- University.

Dr. Mimoza Canga is laureate at the University Sapienza, Roma- Italy and has a $\mathrm{PhD}$ from the University of Tirana. Currently works in the University of Vlore, Department of Public Health, Vlore-Albania 